\title{
A New Ranking ON HeXagonal FuZZY NUMBERS
}

\author{
Dr. Mrs. A.Sahaya Sudha ${ }^{1}$ and Mrs.M.Revathy ${ }^{2}$ \\ ${ }^{1}$ Department of Mathematics, Nirmala College for women, Coimbatore \\ ${ }^{2}$ Department of Mathematics, Dr.N.G.P.Arts and Science College, Coimbatore
}

\begin{abstract}
:
The objective of this paper is to introduce a fuzzy linear programming problem with hexagonal fuzzy numbers. Here the parameters are hexagonal fuzzy numbers and Simplex method is used to arrive an optimal solution by a new method compared to the earlier existing method. This procedure is illustrated with numerical example. This will further help the decision makers to come out with a feasible alternatives with better economical viability.
\end{abstract}

\section{KEY WORDS:}

Fuzzy Number, Hexagonal Fuzzy Number, Fuzzy Linear Programming Problem

\section{INTRODUCTION:}

In a practical situation of a production process a manufacturer has to work out for a minimum investment with maximum realization. In this situation the fuzzy set theory is applied using the membership functions. Since the values are not clear and defined due to uncertainties. A fuzzy linear programming problem (FLPP) model with minimum values are used to get a better orientation towards the result. Zadeh [6] pioneered the first mathematical formulation of fuzziness. And Orlovsky [11] followed with various techniques and tools in the fuzzy set theory to explore the situation practically. This was further research by the various authors and numerous problems pertaining to decision making where discussed by Tamiz [8], Zimmermann [3] and Ross [12]. Senthilkumar and .Rajendran [10] compared fuzzy numbers using ranking function and Verdegay [7] and Maleki et. al, [4] defined the crisp model.

Based on the above a methodology is adopted in solving the FLPP with hexagonal fuzzy numbers.

This paper is framed as follows: Section 2 discusses the basic definitions. In section 3 concepts of hexagonal fuzzy numbers is reviewed. In section 4 the proposed ranking method is discussed. In section 5 formulation of FLPP and algorithm to solve the problem is discussed. To solve this method, a numerical example is solved in section 6. Results are compared in Section 7. Conclusion is discussed in Section 8. 


\section{Preliminaries:}

\subsection{FUZZY SET [1]:}

Let $\mathrm{X}$ be a nonempty set and A fuzzy set $\tilde{F}(\mathrm{X})$ is defined as $\tilde{F}=\left\{\left(x, \mu_{\tilde{F}}(x)\right) / x \in X\right\}$ where $\mu_{\tilde{F}}(x)$ is called the membership function which maps each element of $X$ to a value between 0 and 1

\subsection{FUZZY NUMBER [1]:}

A fuzzy number is a generalized regular real number which refers to a connected set of possible values of weights between 0 and 1 . This weight is called the membership function.

A fuzzy number $\tilde{F}$ is a convex normalized fuzzy set on the real line $\mathrm{R}$ such that:

- There exist at least one $\mathrm{x} \in \mathrm{R}$ with $\mu_{\widetilde{F}}(x)=1$

- $\quad \mu_{\tilde{F}}(x)$ is piecewise continuous

\section{HeXAgONAL FUZZY NUMBERS (HFN):}

\subsection{DEFINITION[9]:}

A fuzzy number $\tilde{F}_{H}$ is a hexagonal fuzzy number denoted by $\tilde{F}_{H}=\left(\mathrm{f}_{1}, \mathrm{f}_{2}, \mathrm{f}_{3}, \mathrm{f}_{4}, \mathrm{f}_{5}, \mathrm{f}_{6}\right)$ where $\mathrm{f}_{1}, \mathrm{f}_{2}, \mathrm{f}_{3}, \mathrm{f}_{4}, \mathrm{f}_{5}$ and $\mathrm{f}_{6}$ are real numbers and its membership function is given below,

$$
\mu_{\tilde{F}}(x)= \begin{cases}\frac{1}{2}\left(\frac{x-f_{1}}{f_{2}-f_{1}}\right), & \text { for } f_{1} \leq x \leq f_{2} \\ \frac{1}{2}+\frac{1}{2}\left(\frac{x-f_{2}}{f_{3}-f_{2}}\right), & \text { for } f_{2} \leq x \leq f_{3} \\ 1, & \text { for } f_{3} \leq x \leq f_{4} \\ 1-\frac{1}{2}\left(\frac{x-f_{4}}{f_{5}-f_{4}}\right), & \text { for } f_{4} \leq x \leq f_{5} \\ \frac{1}{2}\left(\frac{f_{6}-x}{f_{6}-f_{5}}\right), & \text { for } f_{5} \leq x \leq f_{6} \\ 0, & \text { otherwise }\end{cases}
$$

\subsection{DEFINITION [9]:}

A fuzzy set $\widetilde{F}_{H}$ is defined as a set of real numbers with its membership function having the following characteristics

(i) $\mathrm{P}_{1}(\mathrm{u})$ is a bounded left continuous non decreasing function over $[0,0.5]$. 
International Journal of Fuzzy Logic Systems (IJFLS) Vol.6, No.4,October 2016

(ii) $\mathrm{Q}_{1}(\mathrm{v})$ is a bounded left continuous non decreasing function over [0.5,w].

(iii) $\mathrm{Q}_{2}(\mathrm{v})$ is a bounded left continuous non increasing function over $[\mathrm{w}, 0.5]$.

(iv) $\mathrm{P}_{2}(\mathrm{v})$ is a bounded left continuous non increasing function over $[0.5,0]$.

\subsubsection{REMARK [9]:}

When $\mathrm{w}=1$ the hexagonal fuzzy number is a normal fuzzy number

\subsection{Positive And Negative HFN [1]:}

Let $\tilde{F}_{H}=\left(\mathrm{f}_{1}, \mathrm{f}_{2}, \mathrm{f}_{3}, \mathrm{f}_{4}, \mathrm{f}_{5}, \mathrm{f}_{6}\right)$ is positive hexagonal fuzzy number if $\mathrm{a}_{\mathrm{i}}>0$ for $\mathrm{i}=1,2, \ldots, 6$ and it is negative hexagonal fuzzy number if $a_{i}<0$ for $i=1,2, \ldots, 6$.

\subsection{ARITHMETIC OPERATIONS ON HFN [1]:}

Let $\tilde{F}_{H}=\left(\mathrm{f}_{1}, \mathrm{f}_{2}, \mathrm{f}_{3}, \mathrm{f}_{4}, \mathrm{f}_{5}, \mathrm{f}_{6}\right), \tilde{G}_{H}=\left(\mathrm{g}_{1}, \mathrm{~g}_{2}, \mathrm{~g}_{3}, \mathrm{~g}_{4}, \mathrm{~g}_{5}, \mathrm{~g}_{6}\right)$ be two hexagonal fuzzy numbers which performs the following three operations :

$\checkmark$ Addition : $\widetilde{F}_{H}+\widetilde{G}_{H}=\left(\mathrm{f}_{1}+\mathrm{g}_{1}, \mathrm{f}_{2}+\mathrm{g}_{2}, \mathrm{f}_{3}+\mathrm{g}_{3}, \mathrm{f}_{4}+\mathrm{g}_{4}, \mathrm{f}_{5}+\mathrm{g}_{5}, \mathrm{f}_{6}+\mathrm{g}_{6}\right)$

$\checkmark$ Subtraction : $\tilde{F}_{H}-\widetilde{G}_{H}=\left(\mathrm{f}_{1}-\mathrm{g}_{6}, \mathrm{f}_{2}-\mathrm{g}_{5}, \mathrm{f}_{3}-\mathrm{g}_{4}, \mathrm{f}_{4}-\mathrm{g}_{3}, \mathrm{f}_{5}-\mathrm{g}_{2}, \mathrm{f}_{6}-\mathrm{g}_{1}\right)$

$\checkmark$ Multiplication : $\widetilde{F}_{H} * \widetilde{G}_{H}=\left(\mathrm{f}_{1} * \mathrm{~g}_{1}, \mathrm{f}_{2} * \mathrm{~g}_{2}, \mathrm{f}_{3} * \mathrm{~g}_{3}, \mathrm{f}_{4} * \mathrm{~g}_{4}, \mathrm{f}_{5} * \mathrm{~g}_{5}, \mathrm{f}_{6} * \mathrm{~g}_{6}\right)$

\subsection{EXISTING METHOD [11]:}

The magnitude of a HFN $\tilde{F}_{H}=\left(\mathrm{f}_{1}, \mathrm{f}_{2}, \mathrm{f}_{3}, \mathrm{f}_{4}, \mathrm{f}_{5}, \mathrm{f}_{6}\right)$, is defined as $R\left(\widetilde{F}_{H}\right)=\left(\frac{2 f_{1}+3 f_{2}+4 f_{3}+4 f_{4}+3 f_{5}+2 f_{6}}{18}, \frac{5 w}{18}\right)$

\section{Proposed Ranking of Hexagonal Fuzzy Numbers:}

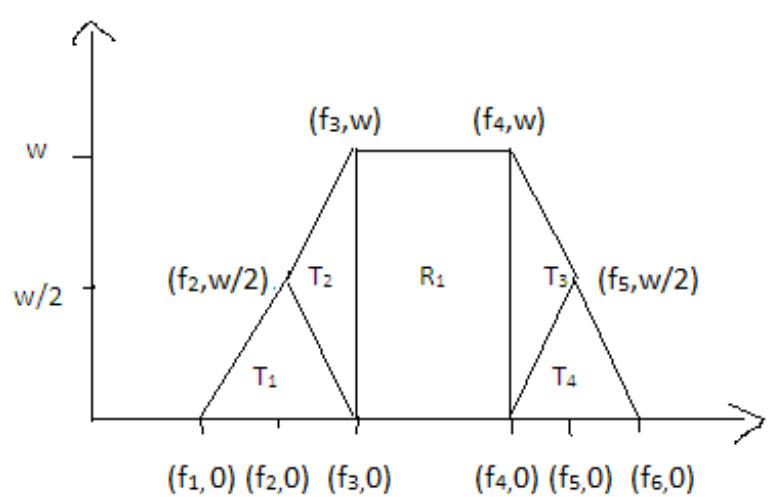

Figure 4.1 Ranking of Hexagonal Fuzzy Numbers 
From Figure (4.1) Hexagon is divided into four triangles and one rectangle. By using the centroid formula of triangle and rectangle we can calculate the ranking as

$T_{1}=\left(\frac{f_{1}+f_{2}+f_{3}}{3}, \frac{w}{6}\right), T_{2}=\left(\frac{f_{2}+2 f_{3}}{3}, \frac{w}{2}\right), T_{3}=\left(\frac{2 f_{4}+f_{5}}{3}, \frac{w}{2}\right), T_{4}=\left(\frac{f_{4}+f_{5}+f_{6}}{3}, \frac{w}{6}\right)$

and $R_{1}=\left(\frac{f_{3}+f_{4}}{2}, \frac{w}{2}\right)$

By adding $T_{1}, T_{2}, T_{3}, T_{4}$ and $R_{1}$ we get the new ranking as

$R\left(\tilde{F}_{H}\right)=\left(\frac{f_{1}+2 f_{2}+3 f_{3}+3 f_{4}+2 f_{5}+f_{6}}{3}+\frac{f_{3}+f_{4}}{2}, \frac{w+w}{6}+\frac{w+w+w}{2}\right)$

Therefore the ranking is $R\left(\tilde{F}_{H}\right)=\left(\frac{2 f_{1}+4 f_{2}+9 f_{3}+9 f_{4}+4 f_{5}+2 f_{6}}{6}, \frac{11 w}{6}\right)$

\section{Formulation Of Fuzzy linear Programming Problem [5]:}

The fuzzy linear programming problem with m fuzzy inequality / equality constrains and $\mathrm{n}$ fuzzy variables may be formulated as,

Maximize (or minimize) $\tilde{z}=\tilde{c}_{1} \tilde{x}_{1}+\tilde{c}_{2} \tilde{x}_{2}+\cdots+\tilde{c}_{n} \tilde{x}_{n}$

$$
\begin{aligned}
& \text { Subject to } \sum_{j=1}^{n} a_{i j} \tilde{x}_{j} \leq \tilde{b}_{i}, i=1,2,3, \ldots, m_{0}, \\
& \sum_{j=1}^{n} a_{i j} \tilde{x}_{j} \geq \tilde{b}_{i}, i=m_{0}+1, m_{0}+2, m_{0}+3, \ldots, m
\end{aligned}
$$

And $\tilde{x}_{j} \geq \tilde{0}$ for all $\mathrm{j}=1,2,3, \ldots, \mathrm{n}$,

Where $\mathrm{a}_{\mathrm{ij}} \in \mathrm{R}, \tilde{c}_{j}, \tilde{x}_{j}, \tilde{b}_{j} \in F(R), \mathrm{i}=1,2,3, \ldots, \mathrm{m}, \mathrm{j}=1,2,3, \ldots, \mathrm{n}$, hence the formulation of FLPP.

\subsection{DEFINITION [5]:}

We consider $\mathbf{S}$ be the set of all fuzzy feasible solutions of (5.1). A fuzzy feasible solution $\tilde{x}_{0} \in \mathbf{S}$ is said to be a fuzzy optimum solution to (5.1) if $\tilde{c} \tilde{x}_{0} \geq \tilde{c} \tilde{x}$ for all $\tilde{x} \in \mathbf{S}$, where $\tilde{c}=\left(\tilde{c}_{1}, \tilde{c}_{2}, \tilde{c}_{3}, \ldots \ldots, \tilde{c}_{n}\right)$ and $\tilde{c} \tilde{x}=\left(\tilde{c}_{1} \tilde{x}_{1}+\tilde{c}_{2} \tilde{x}_{2}+\tilde{c}_{3} \tilde{x}_{3}+\ldots \ldots+\tilde{c}_{n} \tilde{x}_{n}\right)$ 


\subsection{ALgORITHM:}

Step 1: The chosen problem is formulated as the following FLPP

$$
\max \tilde{z} \approx \sum_{j=1}^{n} \tilde{c}_{j} \tilde{x}_{j}
$$

Subject to $\sum_{j=1}^{n} a_{i j} \tilde{x}_{j} \leq \tilde{b}_{i}, i=1,2,3, \ldots, m_{0}$,

$$
\sum_{j=1}^{n} a_{i j} \tilde{x}_{j} \geq \tilde{b}_{i}, i=m_{0}+1, m_{0}+2, m_{0}+3, \ldots, m
$$

And $\tilde{x}_{j} \geq \tilde{0}$ for all $\mathrm{j}=1,2,3, \ldots, \mathrm{n}$,

Step 2: Substituting the value of $\tilde{b}_{i}=\left[\mathrm{b}_{1}, \mathrm{~b}_{2}, \mathrm{~b}_{3}, \mathrm{~b}_{4}, \mathrm{~b}_{5}, \mathrm{~b}_{6}\right]$ and $\tilde{c}_{j}=\left[\mathrm{c}_{1}, \mathrm{c}_{2}, \mathrm{c}_{3}, \mathrm{c}_{4}, \mathrm{c}_{5}, \mathrm{c}_{6}\right]$ in the FLPP obtained in Step 1, we get

$$
\max \tilde{z} \approx \sum_{j=1}^{n}\left[c_{1}, c_{2}, c_{3}, c_{4}, c_{5}, c_{6}\right] \tilde{x}_{j}
$$

Subject to $\sum_{j=1}^{n} a_{i j} \tilde{x}_{j} \leq, \geq,=\left[b_{1}, b_{2}, b_{3}, b_{4}, b_{5}, b_{6}\right]$

$$
\text { and } \tilde{x}_{j} \geq \tilde{0}
$$

Step 3: Using the ranking function (4.1) the FLPP is formulated as

$$
\begin{aligned}
& \max \tilde{z} \approx \sum_{j=1}^{n} R\left[c_{1}, c_{2}, c_{3}, c_{4}, c_{5}, c_{6}\right] \tilde{x}_{j} \\
& \text { Subject to } \sum_{j=1}^{n} a_{i j} \tilde{x}_{j} \leq, \geq,=R\left[b_{1}, b_{2}, b_{3}, b_{4}, b_{5}, b_{6}\right] \\
& \text { and } \tilde{x}_{j} \geq \tilde{0}
\end{aligned}
$$

Step 4: The optimum solution is obtained by solving the above LPP.

\section{NUMERICAL EXAMPLE:}

In a foundary, moulding department produces moulds in two different process conventional and automation with a profit of Rs. 3 / kg and Rs. 4 / kg respectively. Production time of conventional is 10 moulds / hr and automation is 20 moulds / hr. To perform this process the number of labours required is 5 and 2 respectively. Similarly the electricity usage in conventional method is 5 units / $\mathrm{hr}$ and in automation is 15 units / hr. The problem is formulated into FLPP and an optimum solution is obtained. 


\section{Solution :}

Step 1: The given problem is formulated as a LPP $\max \tilde{z}=3 \tilde{x}_{1}+4 \tilde{x}_{2}$

Subject to ,

$$
\begin{aligned}
& 5 \tilde{x}_{1}+2 \tilde{x}_{2} \leq 10 \\
& 5 \tilde{x}_{1}+15 \tilde{x}_{2} \leq 20 \\
& \text { and } \tilde{x}_{1}, \tilde{x}_{2} \geq 0
\end{aligned}
$$

Step 2: The formulated LPP is converted into FLPP

$$
\max \tilde{z}=[1,2,3,3,4,5 ; 1] \tilde{x}_{1}+[2,3,4,4,5,6 ; 1] \tilde{x}_{2}
$$

Subject to

$$
\begin{aligned}
& 5 \tilde{x}_{1}+2 \tilde{x}_{2} \leq[8,9,10,10,11,12 ; 1] \\
& 5 \tilde{x}_{1}+15 \tilde{x}_{2} \leq[18,19,20,20,21,22 ; 1] \\
& \text { and } \tilde{x}_{1}, \tilde{x}_{2} \geq 0
\end{aligned}
$$

Step 3: Using the ranking function (4.1) the FLPP is formulated as

$$
\max \tilde{z}=R[1,2,3,3,4,5 ; 1] \tilde{x}_{1}+R[2,3,4,4,5,6 ; 1] \tilde{x}_{2}
$$

Subject to

$$
\begin{aligned}
& 5 \tilde{x}_{1}+2 \tilde{x}_{2} \leq R[8,9,10,10,11,12 ; 1] \\
& 5 \tilde{x}_{1}+15 \tilde{x}_{2} \leq R[18,19,20,20,21,22 ; 1] \\
& \text { and } \tilde{x}_{1}, \tilde{x}_{2} \geq 0
\end{aligned}
$$

Step 4: Using the proposed ranking method the FLPP is converted into a LPP.

Step 5: The crisp linear programming problem is further solved and the optimal solution is $\mathrm{x}_{1}=15.52, \mathrm{x}_{2}=7.05$ and $\operatorname{Max} \mathrm{z}=685.44$

On analysis of the results the foundry should produce 15.52 moulds in conventional and 7.05 moulds in automation to get the profit of Rs. 685.44 
International Journal of Fuzzy Logic Systems (IJFLS) Vol.6, No.4,October 2016

\section{RESULTS AND DISCUSSION:}

The results of the fuzzy linear programming problem of the numerical example (6), is Tabulated below.

Table 7.1 Comparison table of Existing method and new ranking method

\begin{tabular}{|c|c|c|c|c|}
\hline Method & $\mathrm{X}_{1}$ & $\mathrm{X}_{2}$ & $\mathrm{Z}$ & ranking \\
\hline Existing Method & 0.47 & 0.21 & 0.83 & 2 \\
\hline $\begin{array}{c}\text { Our proposed } \\
\text { method }\end{array}$ & 15.52 & 7.05 & 685.44 & 1 \\
\hline
\end{tabular}

It is obvious from the results, shown in Table 7.1, that by using both the existing method [2] and new ranking method, the rank of the fuzzy optimal solution and fuzzy optimal value are best in new method while it is compared to the existing method [2].as illustrated. This clearly indictes that the new method provides more leverage and better optimization.
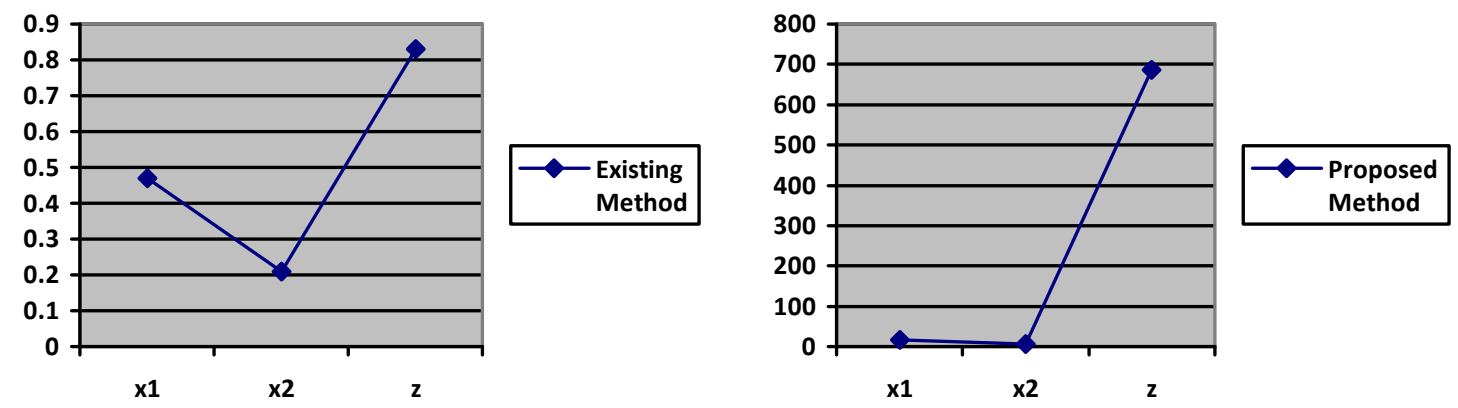

Figure 2. Comparison graph of Existing method and new ranking method

\section{CONCLUSiOn :}

In this paper by using Simplex method we obtain a fuzzy basic feasible solution and the optimal solution obtained is best by new ranking method than the existing method. The decision maker is involved in the decision process which is very useful to apply in a number of practical applications with uncertain informations in marketing, new Project investment and expansion.

\section{REFERENCES}

[1] A.Thamaraiselvi and R.Santhi, (2015) "Optimal solution of Fuzzy Transportation Problem Using Hexagonal Fuzzy Numbers", International Journal of Scientific \& Engineering Research, 6, pp. 4045.

[2] Dr.G.Nirmala and R. Anju, (2014) "An application of fuzzy quantifier in fuzzy Transportation problem”, International Journal of Scientific Research, 3, pp.175-177. 
[3] H.J. Zimmermann, ( 1991) "Fuzzy Set Theory and Its Applications", Boston: Kulwer.

[4] H.R. Maleki, M. Tata, M. Mashinchi, (2000) "Fuzzy Sets and Systems", 9 pp 21-33.

[5] K. Ganesan and P. Veeramani, (2006) "Fuzzy linear programs with trapezoidal fuzzy numbers", pp 305-315.

[6] L. A Zadeh, (1965) "Fuzzy Sets", Information and Control, 8 pp 338-353.

[7] L. Campos and J. L. Verdegay, (1989) "Fuzzy Sets and Systems", 32 pp 1-11.

[8] M. Tamiz, (1996) "Multi-objective programming and goal programming theories and Applications", Germany : Springer-Verlag.

[9] P.Rajarajeswari and A. Sahaya Sudha, (2014) "Ranking of Hexagonal Fuzzy Numbers using Centroid", AARJMD, 1, pp. 265-277.

[10] P. Senthilkumar and G. Rajendran, (2010) "On the solution of Fuzzy linear programming Problem", International journal of computational Cognition, 8(3) pp 45-47.

[11] S. A Orlovsky, (1980) "Fuzzy Sets and Systems", 3 pp 311-321.

[12] T.J. Ross, (1995) "Fuzzy logic with engineering Applications", New York: McGraw-Hill.

\section{AUTHORS BIOGRAPHY}

Dr. A. Sahaya Sudha, Assistant Professor, Department of Mathematics, Nirmala College for women, Coimbatore. She is in the field of Research and Teaching for 19 years. She has published more than 23 papers in various prestigious international journals with high impact factor. She has produced 10 M.Phil. Research scholars with high credibility. Her area of interest includes Operation Research.

M. Revathy, Assistant Professor, Department of Mathematics, Dr.N.G.P. Arts and Science College, Coimbatore. She has on overall teaching experience of 5 years. She has published 5 research papers in various refereed journals. She specializes in Operation Research. 